\title{
Evolution Characteristic Analysis of Pressure-arch of a Double-arch Tunnel in Water-rich
} Strata

\author{
C. L. Li ${ }^{1,2}$, S. R. Wang ${ }^{1,3}$, Z. S. Zou ${ }^{3}$, X. L. Liu ${ }^{3}$ and D. Q. Li $^{4}$ \\ ${ }^{1}$ School of Civil Engineering and Mechanics, Yanshan University, Qinhuangdao 066004, China \\ ${ }^{2}$ Institute of Urban Construction, Hebei Normal University of Science \& Technology, Qinhuangdao 066004, China \\ ${ }^{3}$ Opening Project of Key Laboratory of Deep Mine Construction, Henan Polytechnic University, Jiaozuo 454003, China \\ ${ }^{4}$ School of Mining Engineering, University of New South Wales, NSW 2502, Australia
}

Received 10 January 2016; Accepted 10 March 2016

\begin{abstract}
It is of importance to analyze the morphological characterization, the evolution process and the skewed effect of pressure-arch of a double-arch tunnel in the water-rich strata. Taking a buried depth $80 \mathrm{~m}$ double-arch tunnel as an example, a computational model of the double-arch tunnel was built by using FLAC3D technique. Then considering some aspects including groundwater conditions, tunnel depth, construction sequences and permeability coefficients, the coupling effect of stress field and seepage field in the pressure-arch of the double-arch tunnel was analyzed. The results show that the thickness of the pressure-arch induced by step-by-step excavation and display a step-descent skewed distribution from the left to the right of the double-arch tunnel. The permeability coefficient has a significant influence on the shape and the skewed effect of the pressure arch. The excavation of the bench method has a better arching condition than that of the expanding method. The abtained results provide a basic reference for the rock reinforcement design and safety construction of double-arch tunnels in the water-rich strata.
\end{abstract}

Keywords: Double-arch Tunnel, Pressure-arch, Numerical Simulation, Fluid-solid Coupling, Excavation

\section{Introduction}

Since the double-arch tunnel with a large span has larger pressure in the surrounding rock and the excavation of the left and right tunnels interaction, the force of the supporting system usually is very complicated. Consequently, collapsing and roof caving accidents frequently happen in the weak surrounding rock [1]. Especially for the water-rich strata, the coupling effect of the seepage field and the stress field in the surrounding rock of the double-arch tunnel may lead to a larger deformation and higher risk. A large number of engineering practices showed that the fluid-solid coupling effect is very important for the double-arch tunnel excavation in the water-rich strata.

At present, considering the permeability of the surrounding rock of a tunnel, numerous works have been done and many achievements have been obtained on the tunnel excavation. For example, Lee et al. studied the seepage field distribution and the seepage force in the excavation process of the shallow-buried tunnel and the underwater circular tunnel [2]. Fahimifar et al. derived an analytical solution of the underwater tunnel under the axisymmetric plane strain condition, taking into account the permeability variation in the surrounding rock caused by the coupling effect of the penetration force and the hydraulic force. It applied the strain-softening models and Hoek-Brown empirical strength criterion to describe the surrounding rock behavior. They found that the tunnel stability depended on the seepage and the pore pressure, especially under a high hydraulic gradient

\footnotetext{
*E-mail address: Iclcc_010@163.com ISSN: 1791-2377 @ 2016 Eastern Macedonia and Thrace Institute of Technology. All rights reserved.
}

condition [3]. Based on the derivation of the closed analytical solution and the numerical analysis, Arinoi et al. studied the distribution of the pore pressure of the surrounding rock under different drainage conditions [4]. Fernandez et al. believed that the reasons of an inaccurate water inflow forecast were without considering the hydraulic coupling effect of the rock joints. They analyzed the mechanical properties of the joints under the hydraulic coupling, and deduced the correct analytical solution of the water inflow and the pore pressure distribution. The solutions based on that the surrounding rock permeability decreased under non-supporting excavation condition, and these results were verified through on-site measurements and numerical simulation [5]. Yoo et al. revealed the direct relationship between the water level and the surface subsidence by a three-dimensional finite element model for coupling analysis of the stress and the pore pressure [6].

Using the rock failure analysis program (RFPA), Zhu et al. studied the evolution mechanism of an excavation damage zone for a circular well under hydraulic coupling conditions, and pointed out that the permeability changes of the surrounding rock were affected by two different mechanisms [7]. Based on the discrete fracture network (DFN) model, Yang et al. investigated the equivalent permeability coefficients and the destruction tensor of a sandstone roadway [8]. Based on Xiamen subsea tunnel, Li et al. built a quasi-three-dimensional model, they pointed out the stress size and plastic zone scope varied greatly whether considering the coupling effect of the stress and the pore pressure or not [9]. Ji believed that the coupling effect of the supporting structure, water and the surrounding rock should be considered during the tunnel excavation in the water-rich strata [10]. Li et al. found that the seepage effect of the underground water has a great influence on the tunnel 
deformation, and the excavation of the pilot heading has the most direct and obvious influence on the seepage field of the surrounding rock [11]. Ji et al. suggested that the pore pressure around the tunnel greatly reducing should be avoided owing to harmful impacts on the surface existing building structures [12]. Based on field measurements and fluid-solid coupling numerical analysis, Zhang et al. studied the relationship between high drainage method and the tunnel stability under different water level conditions [13]. Using the Soilworks software, Lai et al. pointed out that the controlled drainage scheme could reduce the action of the groundwater and had a remarkable effect on controlling the tunnel deformation and significantly reduced the plastic areas of the excavation [14].

As a brief summary, the relevant research on tunnel in the water-rich strata mostly focused on the water inflow forecasting, drainage construction and tunnel stability problems. However, these studies on the morphological characteristics and dynamic evolution mechanism of the pressure-arch induced by the step-by-step excavation of a double-tunnel in the water-rich strata were rarely reported. Taking the double-arch tunnel in the water-rich strata as an example, considering the fluid-solid coupling effect, the evolution mechanism analysis of the pressure-arch by tunnel step-by-step excavation were carried out in this paper. The remainder of this paper is organized as follows. Section 2 describes the computational model and numerical analysis schemes. Section 3 gives the results and discussion of the pressure-arch evolution characteristics of the double-arch tunnel in the water-rich strata. Conclusions are summarized in Section 4.

\section{Materials and methods}

\subsection{The computational model}

The cross-section of a double-arch tunnel to be modelled is shown in Figure 1a. The double-arch tunnel is $9.8 \mathrm{~m}$ high and $25.5 \mathrm{~m}$ wide. The surrounding rock of the tunnel is mainly composed of moderately weathered sandstone. Figure $1 \mathrm{~b}$ shows the major part of the numerical model being treated as a plane problem. In the global coordinate system, the model dimensions are defined as $125 \mathrm{~m} \times 1 \mathrm{~m} \times$ $142 \mathrm{~m}$ in the $x$-, $y$-, and $z$-axis direction respectively. The horizontal movement of the model was restricted, the model bottom was fixed, and the upper surface of the model was the load boundary applied the uniform load to simulate the weight of the overburden rock. The groundwater conditions were considered in the model by applying the fixed water head on both boundaries of the model, which varied linearly from top-down with depth, and the bottom is an impermeable boundary. In the calculation process, five monitoring lines were set to track the thickness variation of the pressure-arch with tunnel step-by-step excavation.

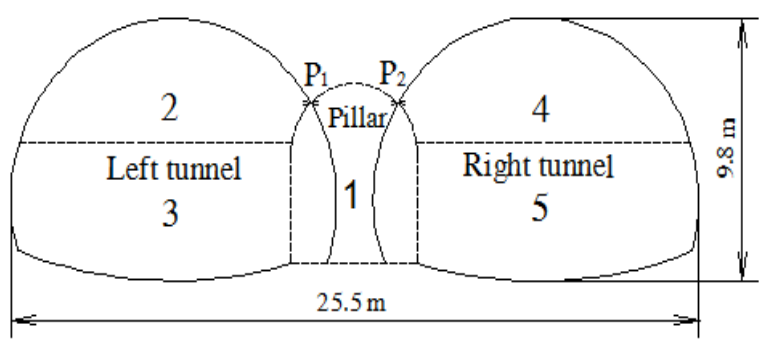

(a) Excavation scheme of the tunnel

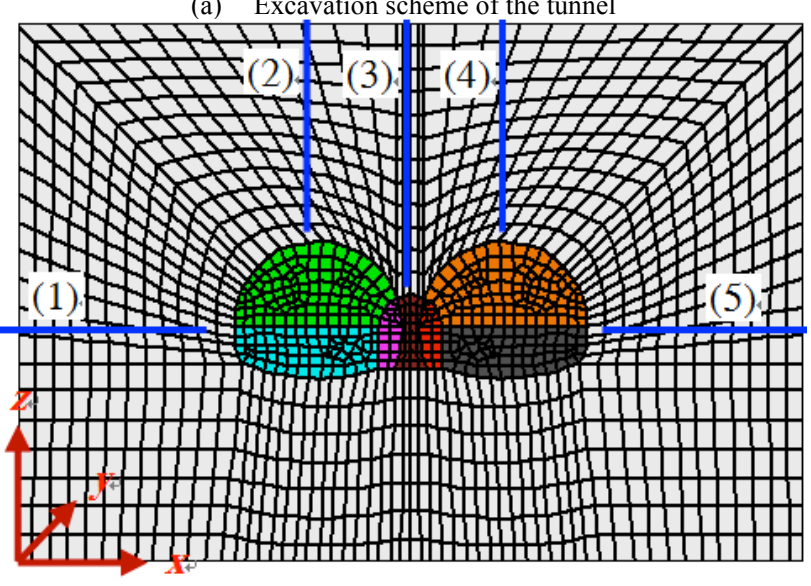

(b) The computational model and monitoring lines

Fig.1. Excavation scheme of the tunnel and schematic of the computational model.

The physical, mechanical and hydraulic parameters of the highway double-tunnel were selected as listed in Table 1.

Table 1. Physical and mechanical parameters of the soil of the pit

\begin{tabular}{l|l|l|l|l|l|l}
\hline $\begin{array}{l}\text { Density } \\
\left(\mathbf{k N} / \mathbf{m}^{3}\right)\end{array}$ & $\begin{array}{l}\text { Elasticity modulus } \\
(\mathbf{G P a})\end{array}$ & Poisson ratio & $\begin{array}{l}\text { Friction angle } \\
\left({ }^{\circ}\right)\end{array}$ & $\begin{array}{l}\text { Cohesion } \\
(\mathbf{M P a})\end{array}$ & $\begin{array}{l}\text { Tension } \\
(\mathbf{M P a})\end{array}$ & $\begin{array}{l}\text { Permeability coefficient } \\
(\mathbf{c m} / \mathbf{s})\end{array}$ \\
\hline 25.00 & 10 & 0.25 & 45 & 1.20 & 0.50 & $3.0 \times 10^{-5}$ \\
\hline
\end{tabular}

\subsection{Pressure-arch parameters of the double-arch tunnel} For the sake of simplicity, the element stress variable $e$ is defined as

$$
e=\frac{\sigma_{\max }-\sigma_{\min }}{\sigma_{\max }} \times 100 \%
$$

where $\sigma_{\max }$ and $\sigma_{\min }$ are the maximum and the minimum principal stress in the surrounding rock respectively after the double-arch tunnel being excavated [15].
In this study, the pressure-arch shape in the surrounding rock of a double-arch tunnel is simplified as that shown in Figure 2, in which the pressure-arch of the double-arch tunnel is divided into three zones. For Zone 1, the characteristic parameters of the pressure-arch are defined as the vault thickness $S_{1}$, the waist thickness $S_{2}$ and the skewback thickness $S_{3}$, respectively. It is the same for Zone 2 and Zone 3. The inner boundary of pressure-arch is defined as the line of the major principal stress peaks. From the stress variation perspective, the element stress variable $e$ $=15 \%$ is regarded as the outer boundary of the pressurearch. On both lateral wall corners of the double-arch tunnel, the side boundary extends towards the depth of the 
surrounding rock and meets the inner and outer boundaries of the pressure-arch along the rock rupture angle $\beta$. According to the Rankine soil pressure theory, the rock rupture angle is $\beta=45^{\circ}+\frac{\varphi}{2}$, where $\varphi$ is the inner friction angle of the surrounding rock of the double-arch tunnel.

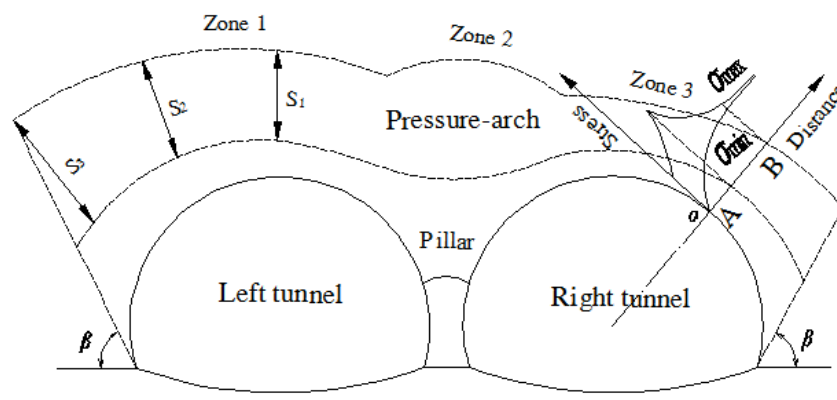

Fig. 2. Pressure-arch zones and morphological parameters of the double-arch tunnel.

\subsection{Simulation analysis schemes}

In the numerical calculation, the assumptions were as follows:

(1) The surrounding rock behavior followed the MohrCoulomb strength criterion.

(2) The tunnel was in hydrostatic stress state, namely the lateral pressure coefficient $\lambda$ was 1.0.

(3) The surrounding rock was in the water-rich strata during the excavation process.

The buried depth, excavation sequence and permeability coefficient were all considered to study the morphological evolution of the pressure-arch of the double-arch tunnel. The selected calculation conditions were listed in Table 2.

Table 2. The numerical simulation conditions

\begin{tabular}{|c|c|}
\hline Conditions & Contents of Simulation \\
\hline Depth variation & $\begin{array}{l}\text { Bench method stepwise excavation, } \\
\text { permeability coefficient of } 3.0 \times 10^{-6} \mathrm{~cm} / \mathrm{s} \text {, } \\
\text { different depths of } 2.5 D, 4 D \text { or } 6 D .\end{array}$ \\
\hline $\begin{array}{l}\text { Excavation } \\
\text { sequence }\end{array}$ & $\begin{array}{l}\text { Using bench method or expanding method } \\
\text { excavation, surrounding rock permeability } \\
\text { coefficient of } 3.0 \times 10^{-6} \mathrm{~cm} / \mathrm{s} \text {, depth of } 2.5 \mathrm{D} \text {. }\end{array}$ \\
\hline $\begin{array}{l}\text { Permeability } \\
\text { coefficient }\end{array}$ & $\begin{array}{l}\text { Bench method stepwise excavation, depth of } \\
2.5 D \text {, surrounding rock permeability } \\
\text { coefficient of } 3.0 \times 10^{-6} \mathrm{~cm} / \mathrm{s}, 3.0 \times 10^{-5} \mathrm{~cm} / \mathrm{s} \\
\text { or } 3.0 \times 10^{-4} \mathrm{~cm} / \mathrm{s} \text {. }\end{array}$ \\
\hline Saturation and dry & $\begin{array}{l}\text { Bench method stepwise excavation, depth of } \\
2.5 D \text {, surrounding rock permeability } \\
\text { coefficient of } 3.0 \times 10^{-6} \mathrm{~cm} / \mathrm{s} \text {, saturation or dry. }\end{array}$ \\
\hline Note & $D$ was the width of the double-arch tunnel. \\
\hline
\end{tabular}

\section{Results and discussion}

3.1 The influence of groundwater on the pressure-arch The bench excavation process was divided into five steps as shown in Figure 3:

Step 1 as shown in Figure 3a, after the pilot tunnel being excavated, due to the stress self-adjusting effect of the surrounding rock, a symmetrical pressure-arch gradually formed at the top of the pilot tunnel.
Step 2, after the middle wall of the double-arch tunnel being constructed (Figure 3b), section 2 of the left tunnel was excavated. Then the pressure-arch of the left tunnel formed and gradually developed, the pressure-arch thickness of the pilot tunnel increased.

Step 3, after section 3 of the left tunnel being excavated (Figure 3c), the disturbed area of pressure-arch in the surrounding rock increased, and the left side pressure-arch basically formed around the left tunnel. The stress on the top of the pilot tunnel significantly concentrated, indicating that the stress of the middle wall increased significantly.

Step 4, after section 4 of the right tunnel being excavated (Figure 3d), the disturbed area of the pressure-arch further increased and the pressure-arch of the left tunnel continued to rise and the thickness of the pressure-arch further increased. At the same time, the pressure-arch of the right tunnel was connected to the left one and formed a skewed asymmetric compound pressure-arch.

Step 5, after section 5 of the right tunnel being excavated (Figure 3e), the thickness of the pressure-arch significantly increased, indicating that the stress of the right tunnel at this stage was significantly adjusted. But the thickness of the pressure-arch of the left tunnel was higher than that of the right tunnel, namely the compound pressure-arch of the double-arch tunnel showed an obvious skewed distribution.

By comparing Figures 3 and 4, we can see that the evolution process of the pressure-arch of the double-arch tunnel in the water-rich strata is similar to that under the dry condition. However, in comparison with the dry condition, the pressure-arch thickness under the saturated water condition is greater and the pressure-arch shape is not sleek and the skewed characteristics are more obvious.

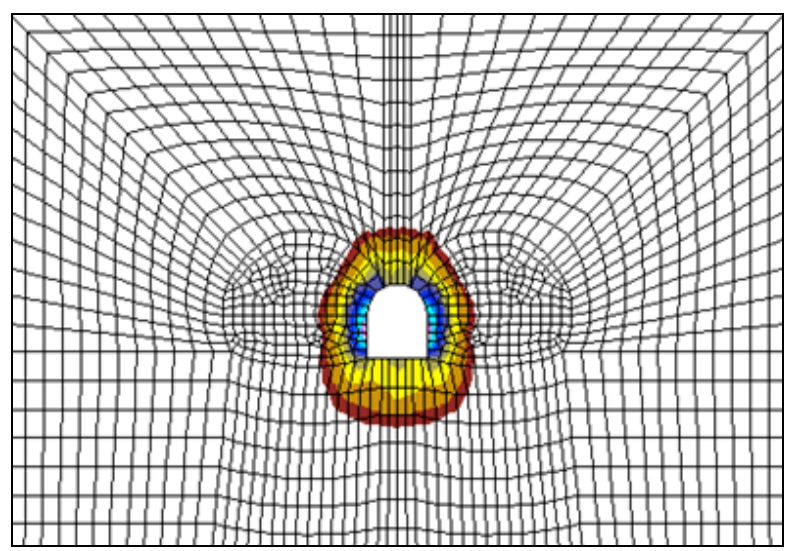

(a) Step 1

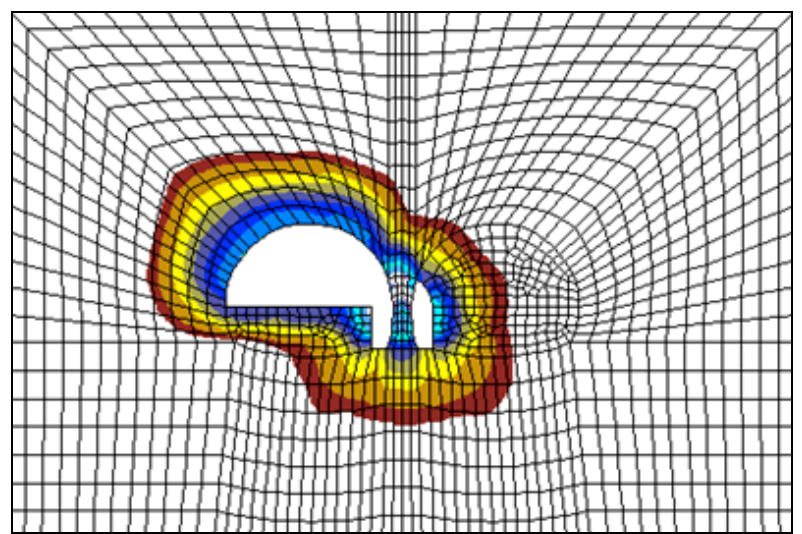

(b) Step 2 


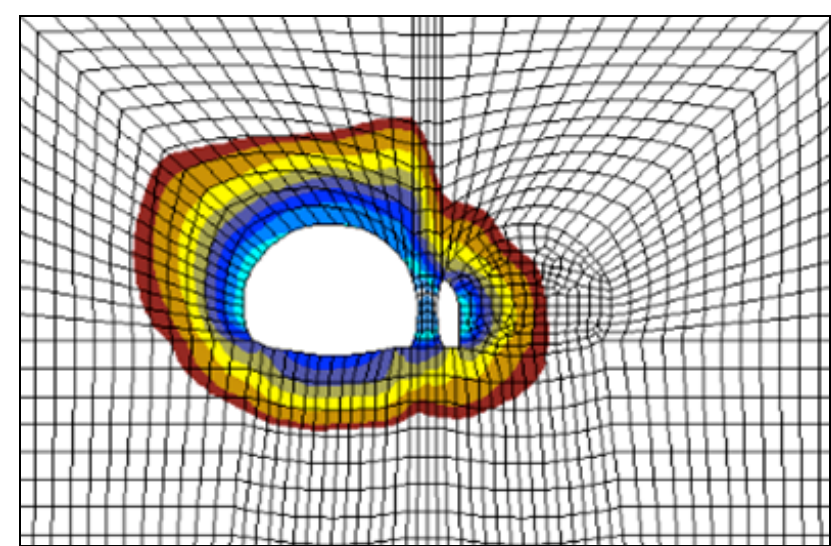

(b) Step 3

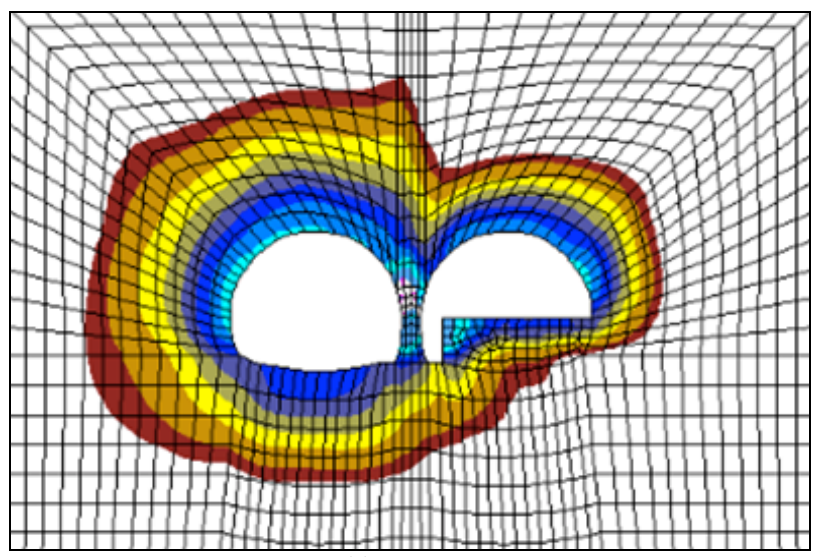

(c) Step 4
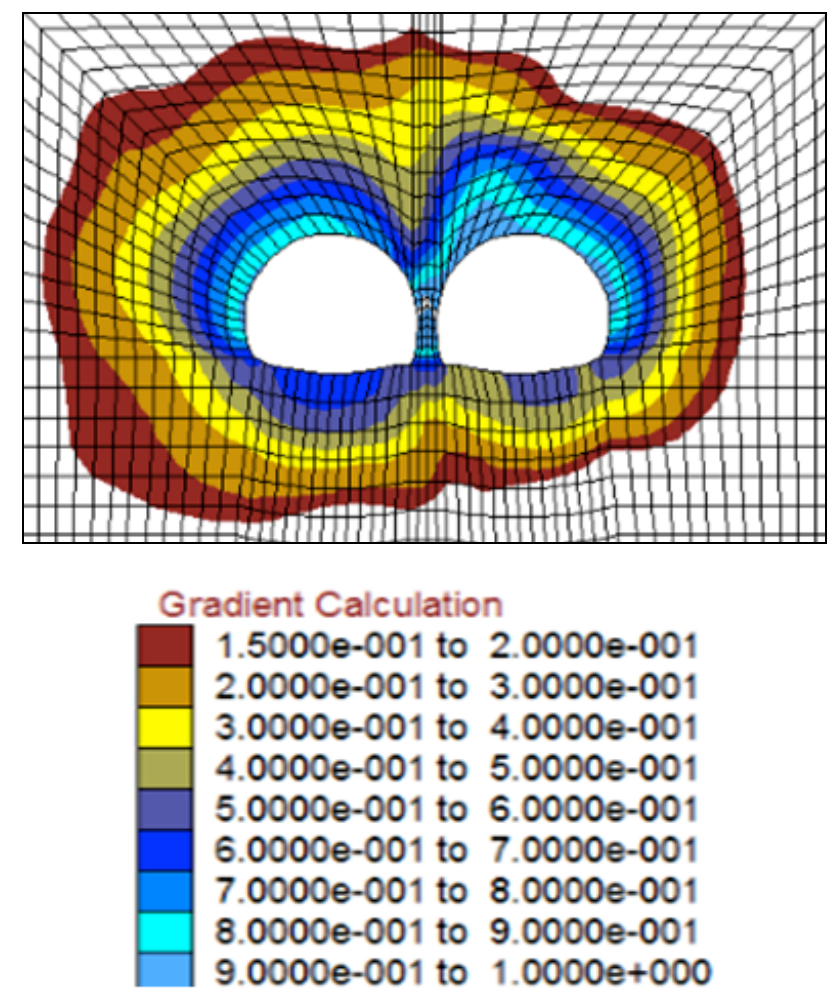

(e) Step 5

Fig.3. Pressure-arch evolution process with bench method excavation under the saturated condition.

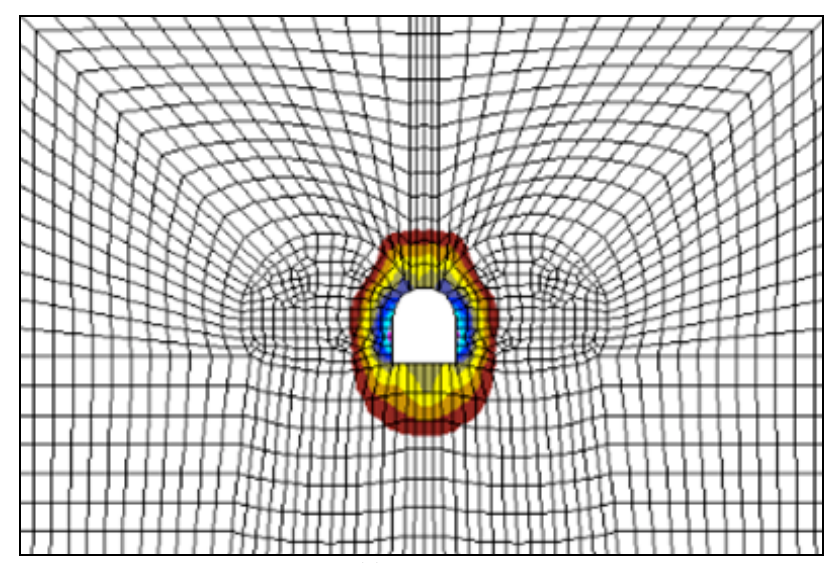

(a) Step 1

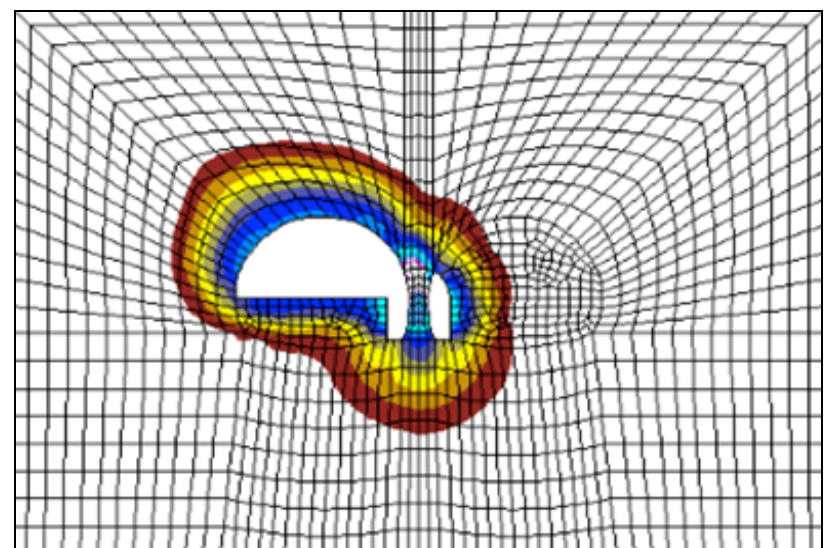

(b) Step 2

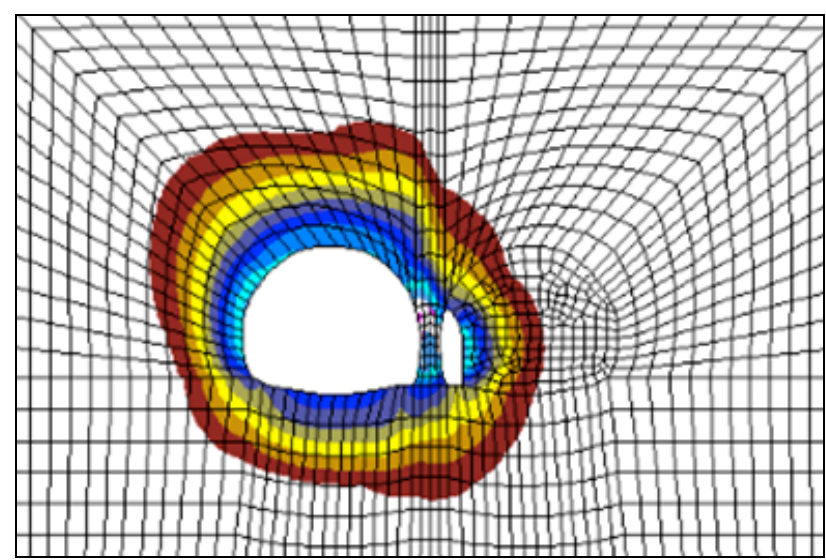

(c) Step 3

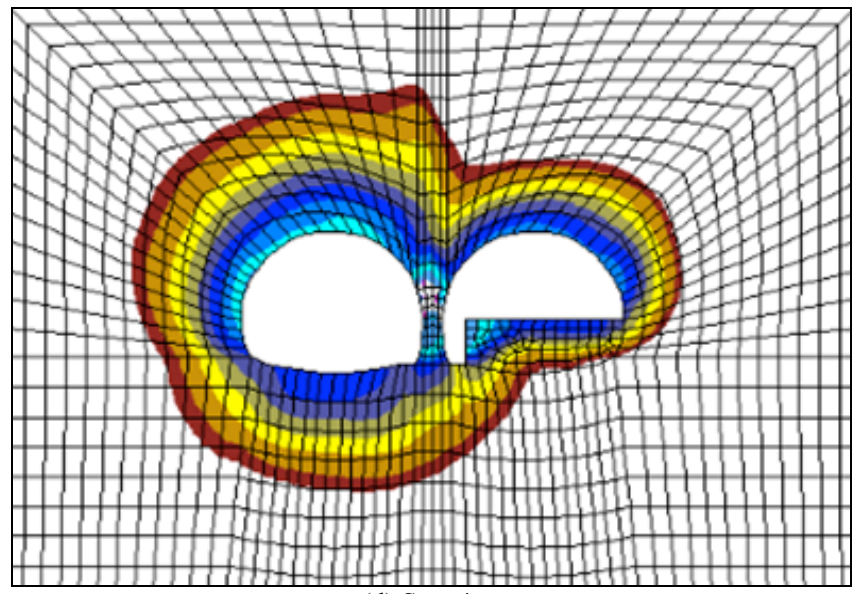

(d) Step 4 

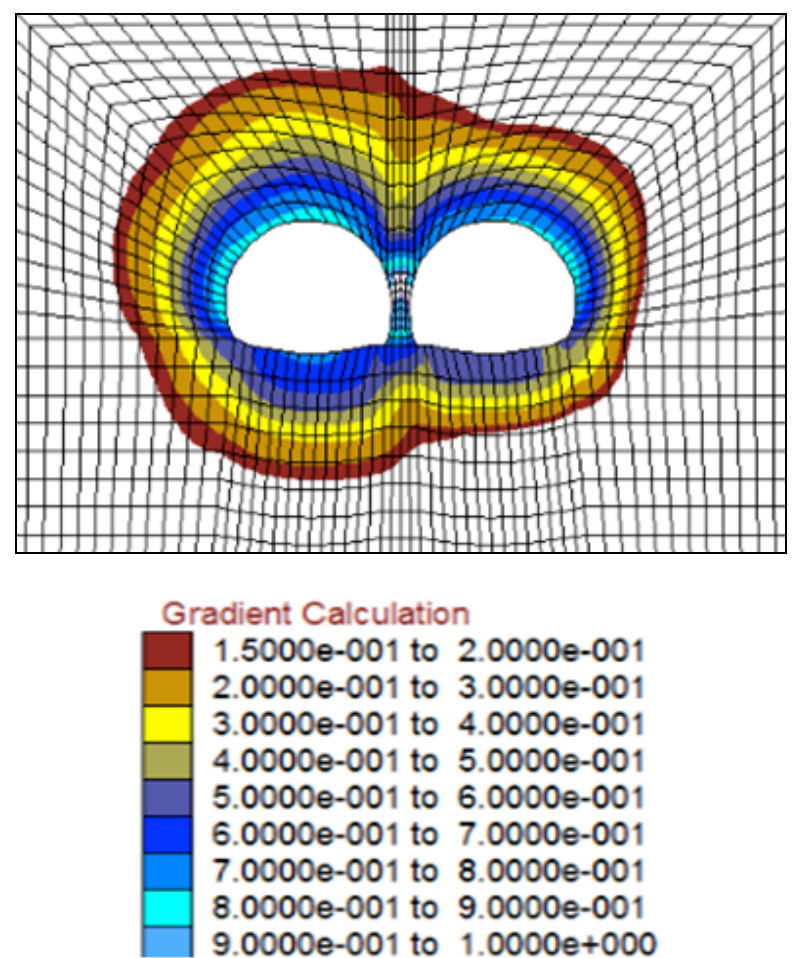

(e) Step 5

Fig.4. Pressure-arch evolution process with bench method excavation under the dry condition.

Taking the left vault thickness $S_{1}$ as an example, $S_{1}$ is approximately $14.23 \mathrm{~m}$ under the saturation condition (Figure 5a), and $S_{1}$ is approximately $11.34 \mathrm{~m}$ under the dry condition (Figure 5b), indicating that the groundwater actions seriously affects the pressure-arch of the double-arch tunnel and increases $S_{1}$ by about $25.5 \%$.

As shown in Figure 6, by comparing the pressure-arch thickness $S_{1}$ along the monitoring line (1), line (5) and line (2), it can be seen that in comparison with the dry condition, the pressure-arch thickness $S_{1}$ under the saturation condition significantly increased, indicating that the self-stability of the surrounding rock weakened for the fluid-solid coupling effect, and more surrounding rock masses were mobilized to form the thicker pressure-arch, therefore the pressure-arch thickness $S_{1}$ under the saturation condition is greater.

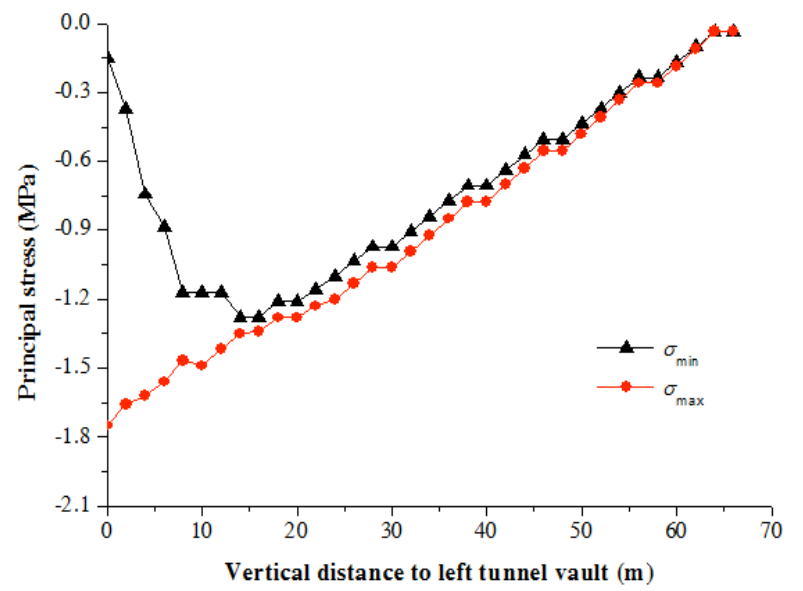

(a) Saturation condition

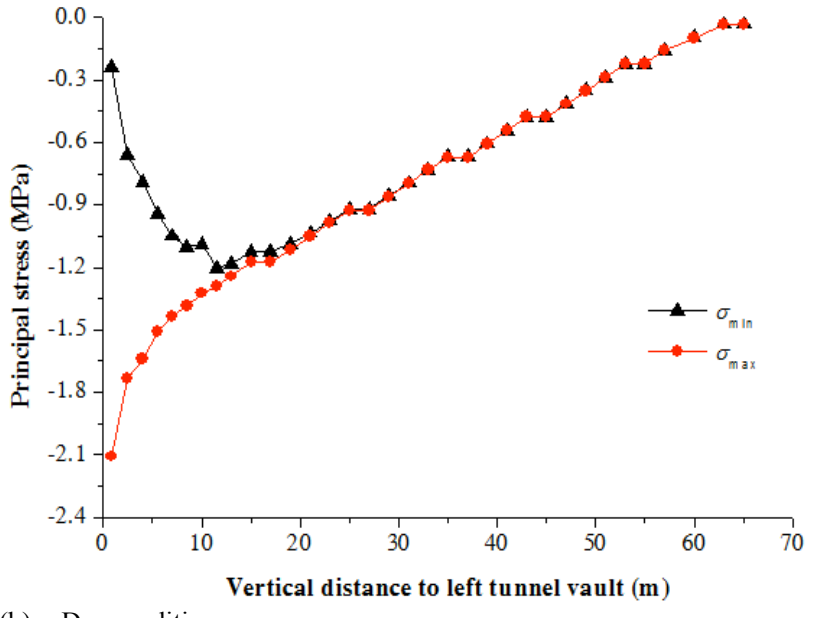

(b) Dry condition

Fig. 5. The maximum and minimum principal stress of the left vault of the double-arch tunnel after excavation

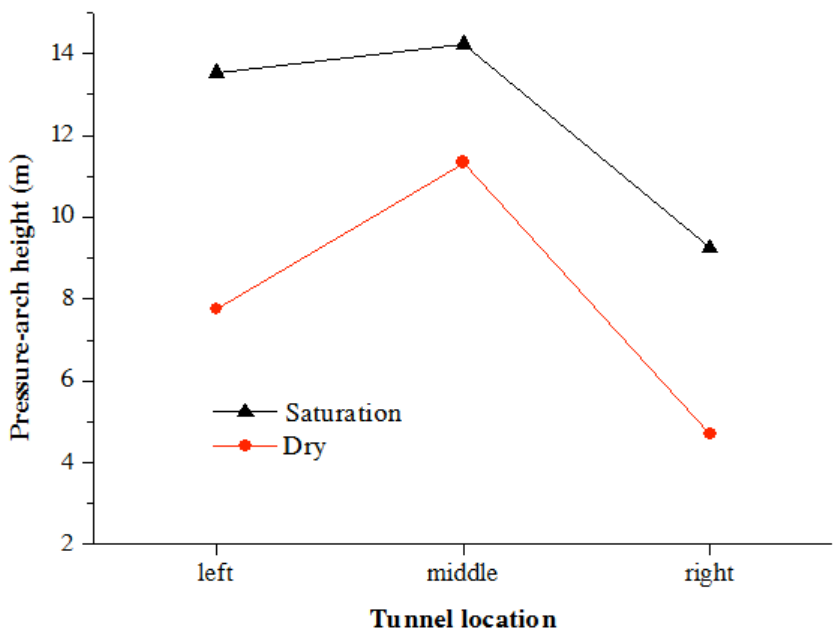

Fig. 6. Pressure-arch thickness variation curves under different conditions.

3.2 Evolution characteristics of the pressure-arch under different buried depth

The evolution characteristics of the pressure-arch of the double-arch tunnel under the buried depth of $2.5 \mathrm{D}(66.7 \mathrm{~m})$, $4 D(102 \mathrm{~m})$ and $6 D(153 \mathrm{~m})$ separately were analyzed in the water-rich strata below.

As shown from Figure 7 that the outer boundary of the pressure-arch in the surrounding rock increased with the buried depth increasing, in comparison, the pressure-arch thicknesses at both sides of the double-arch tunnel increases obviously with the buried depths, and the arch shoulder and arch foot also grow to the deeper surrounding rock.

The pressure-arch thicknesses $S_{1}$ along the monitoring line (1), line (5) and line (2) under three buried depths were shown in Figure 8. The results showed that the left side thickness $S_{1}$ variation of the pressure-arch was more significant and the increased value was the largest with depth increasing. The $S_{1}$ value of the $6.0 \mathrm{D}$ depth increased $60.6 \%$ relative to that of $H=2.5 D$. The $S_{1}$ increased value of the right side of the pressure-arch followed, and the $S_{1}$ of $H=6.0 D$ increased $24 \%$ compared to that of $H=2.5 D$. With the depth variation from $2.5 D$ to $6.0 D$, the thickness ratio of the left and right sides of the pressure-arch increased from 1.46 to 1.90 , so the skewed effect of the pressure-arch of the double-arch tunnel increases with depth increasing in the water-rich strata. 


\subsection{Construction sequence effect}

In this study, both the bench method and the expanding method excavations were considered, in which the first two excavation steps were the same. Figure 9 showed the pressure-arch shape evolution of the last three steps of expanding method, in which the right tunnel excavation earlier than bench method resulted in fairly symmetrical pressure-arch shape and a less skewed effect.

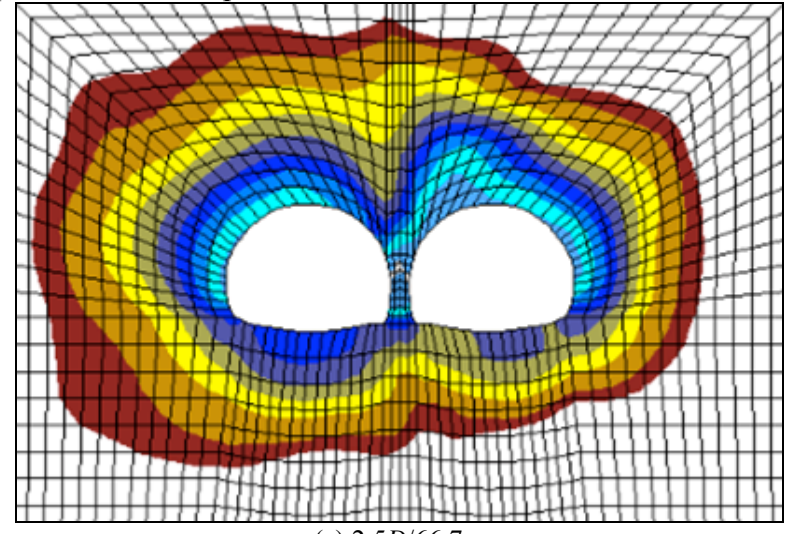
(a) $2.5 D / 66.7 \mathrm{~m}$

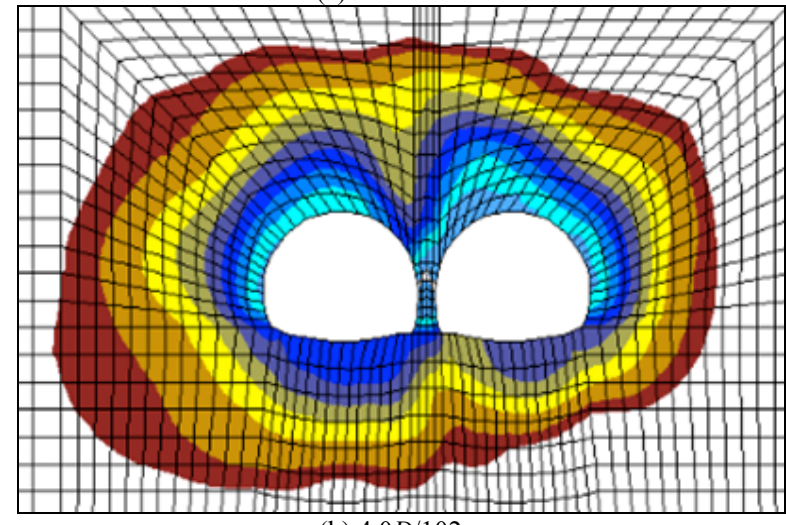
(b) $4.0 \mathrm{D} / 102 \mathrm{~m}$

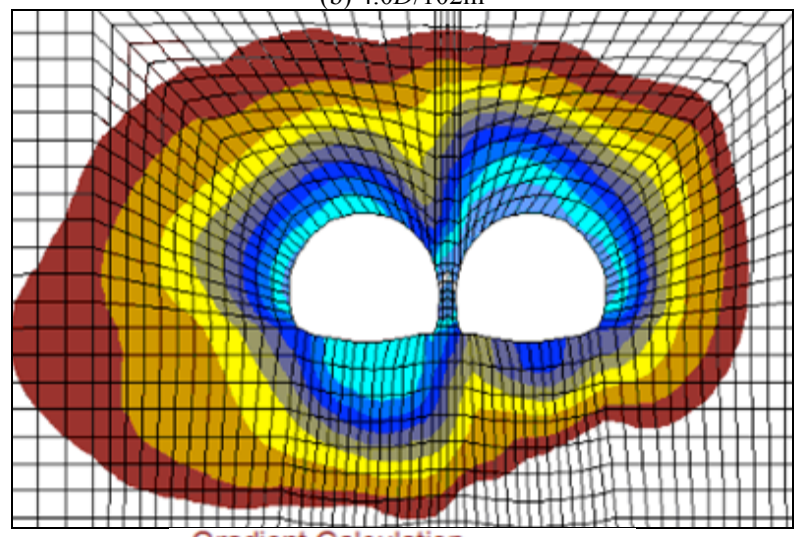

Gradient Calculation

$1.5000 e-001$ to $2.0000 e-001$

$2.0000 e-001$ to $3.0000 e-001$

$3.0000 e-001$ to $4.0000 e-001$

$4.0000 \mathrm{e}-001$ to $5.0000 \mathrm{e}-001$

$5.0000 e-001$ to $6.0000 e-001$

$6.0000 \mathrm{e}-001$ to $7.0000 \mathrm{e}-001$

$7.0000 \mathrm{e}-001$ to $8.0000 \mathrm{e}-001$

8.0000 e-001 to $9.0000 e-001$

$9.0000 \mathrm{e}-001$ to $1.0000 \mathrm{e}+000$

(c) $6.0 \mathrm{D} / 153 \mathrm{~m}$

Fig.7. Pressure-arch variations of the double-arch tunnel with buried depth increasing.

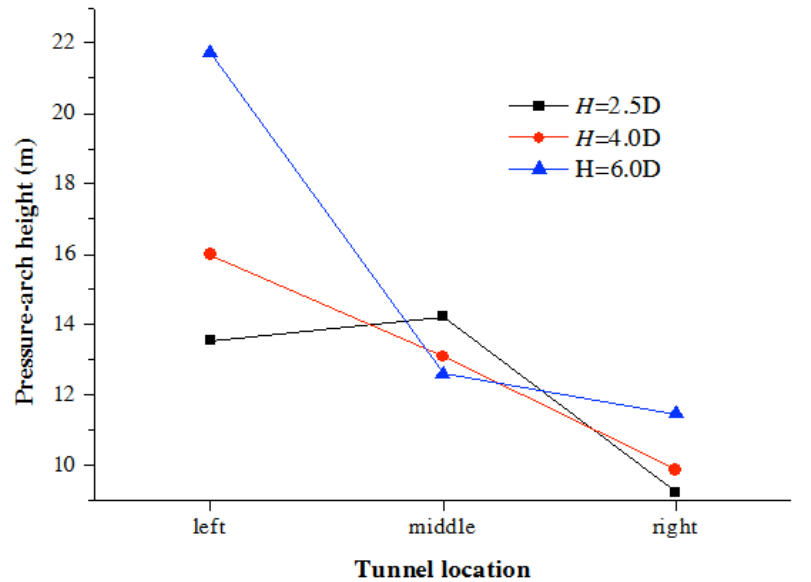

Fig.8. Pressure-arch thickness variation curves with the buried depth increasing.
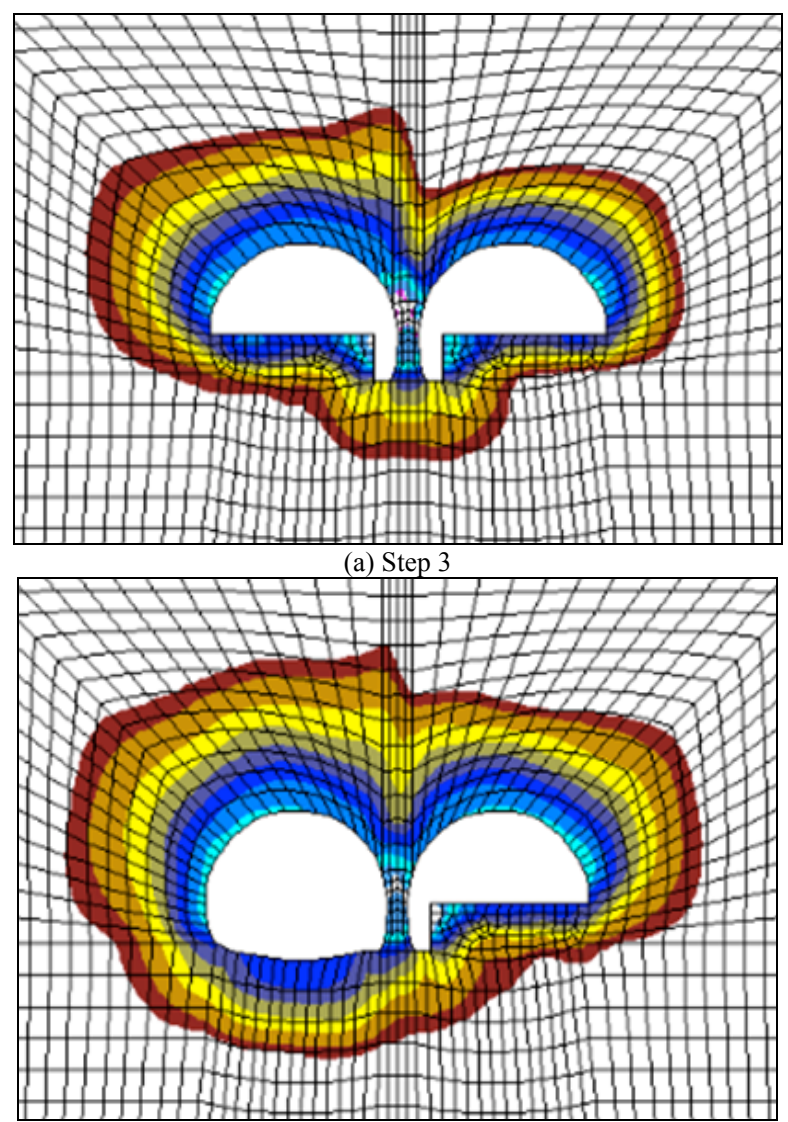

(b) Step 4

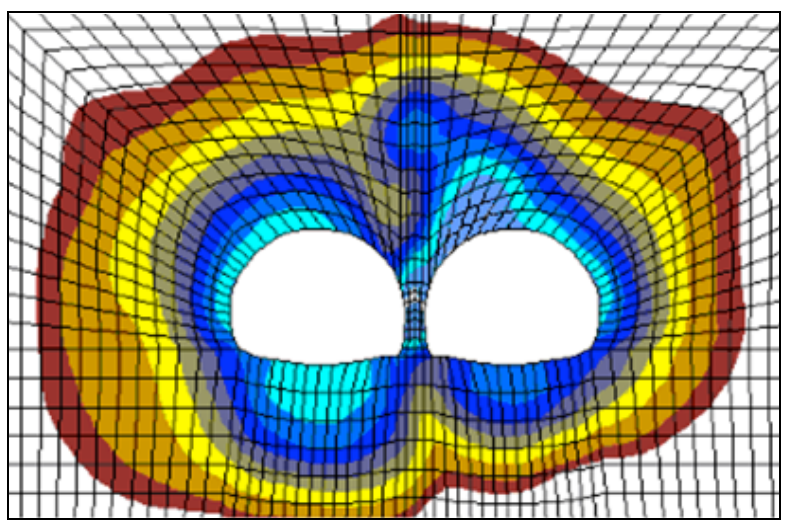




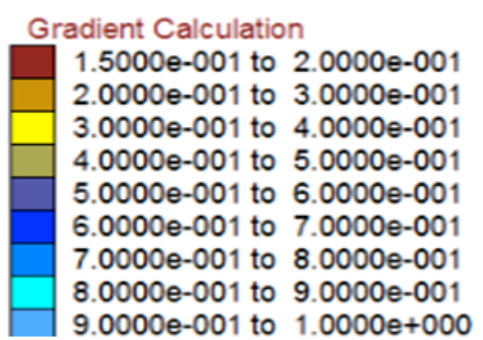

(c) Step 5

Fig.9. Pressure-arch evolution characteristics with the expanding method in the water-rich strata.

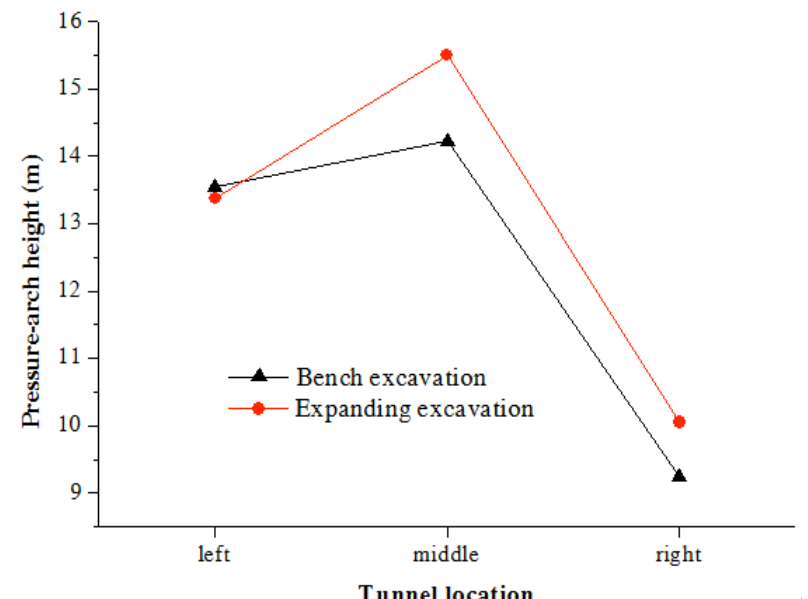

Fig.10. Pressure-arch thickness variation curves with different construction sequences.

The pressure-arch thicknesses $S_{1}$ along the monitoring line (1), line (5) and line (2) under two construction sequences were shown in Figure 10. The results showed that the pressure-arch thickness $S_{1}$ of the expanding method excavation was larger than that of the bench method, as a result of more bigger free face with earlier excavation of the right tunnel and more deeper distribution in the surrounding rock, where more rock mass were mobilized to form the pressure-arch, thus the expanding excavation was not good for the self-stability of the surrounding rock than that of the bench method.

\subsection{Permeability coefficient effect}

Considering permeability coefficients of the surrounding rock are $3.0 \times 10^{-6} \mathrm{~cm} / \mathrm{s}, 3.0 \times 10^{-5} \mathrm{~cm} / \mathrm{s}$ and $3.0 \times 10^{-4} \mathrm{~cm} / \mathrm{s}$ separately, the pressure-arch evolution characteristics of the double-arch tunnel are analyzed.

It can be seen from Figure 11 that the skewed features of pressure-arch of the double-arch tunnel were increasing with the permeability coefficient increasing. With a larger permeability coefficient, the surrounding rock stress is affected more and the pressure arch range enlarges, showing a disadvantage for the surrounding rock stability.

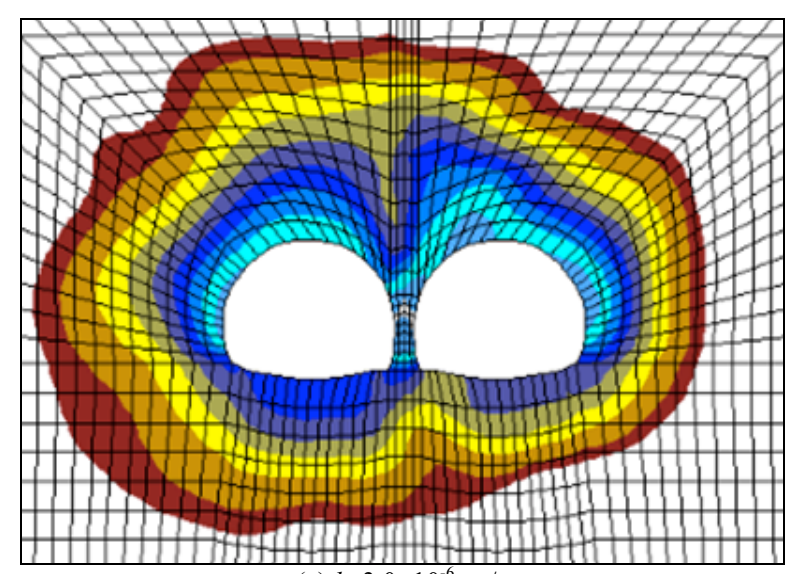

(a) $k=3.0 \times 10^{-6} \mathrm{~cm} / \mathrm{s}$

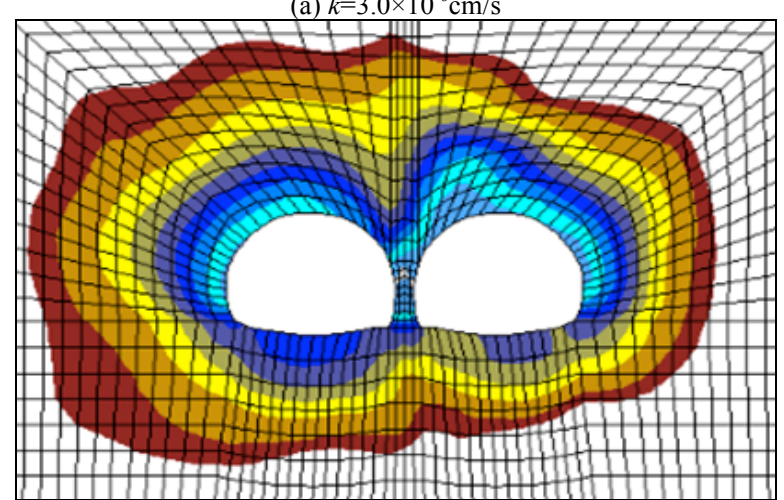

(b) $k=3.0 \times 10^{-5} \mathrm{~cm} / \mathrm{s}$

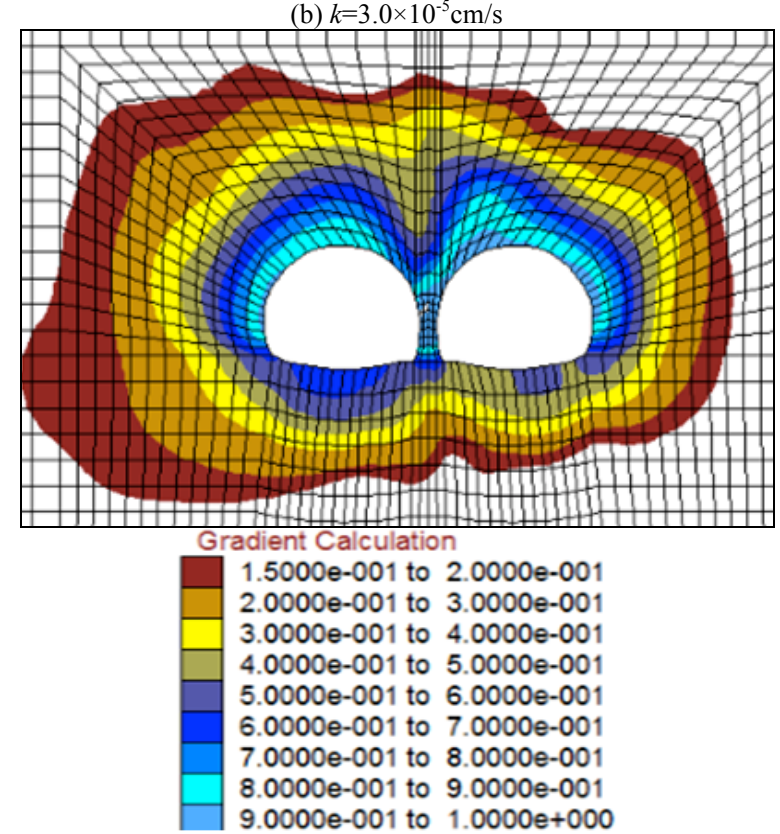

(c) $k=3.0 \times 10^{-4} \mathrm{~cm} / \mathrm{s}$

Fig.11. Pressure-arch characristics variation with different permeability coefficient.

The pressure-arch thicknesses $S_{1}$ along the monitoring line (1), line (5) and line (2) under different permeability coefficients were shown in Figure 12. The results showed that with the permeability coefficients increasing, the left side and right side thicknesses $S_{1}$ of pressure-arch increased significantly, whereas the vault thickness $S_{1}$ of the pressurearch substantially remained the same. 


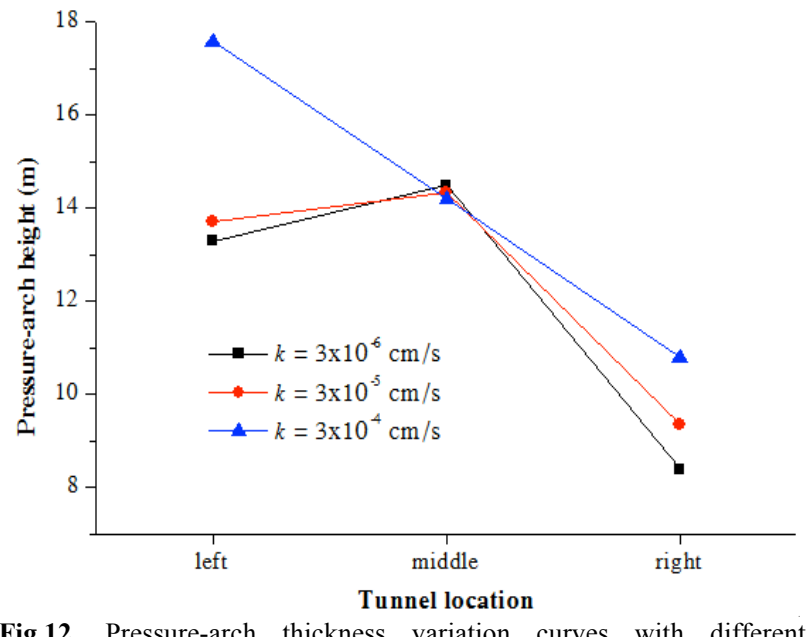

Fig.12. Pressure-arch thickness variation curves with different permeability coefficient.

\section{Conclusions}

The double-arch tunnel being excavated step-by-step would induce the interaction of the stress and the pore pressure and gradually formed compound pressure-arch in the water-rich strata. The height and the thickness of pressure-arch of the double-arch tunnel showed skewed characteristics with the step descending from the left to right tunnel.

The saturation condition and the permeability coefficient had a significant effect on the skewed effect of the pressurearch, the arching prerequisite under the saturation condition showed the opposite trend compared to that of the dry condition.

The pressure-arch in the surrounding rock of the waterrich strata was affected by the buried depth and excavation sequence of the tunnel and the bench method had a better arching condition than that of the expanding method.

\section{Acknowledgements}

This work was financially supported by the National Natural Science Foundation of China (51474188; 51074140; 51310105020), the Natural Science Foundation of Hebei Province of China (E2014203012), the Doctoral Fund of Henan Polytechnic University (B2015-67), and Program for Taihang Scholars. All these are gratefully acknowledged.
1. Wang, Y. Q., and Xie, Y. L., "Research and development of multiarch tunnel in our country", Highway, (6), 2008, pp. 216-219.

2. Lee, I. M., and Nam, S. W., "Effect of tunnel advance rate on seepage forces acting on the underwater tunnel face", Tunnelling and Underground Space Technology, 19(2), 2004, pp. 273-281.

3. Fahimifar, A., and Zareifard, M. R., "A theoretical solution for analysis of tunnels below groundwater considering the hydraulicmechanical coupling", Tunnelling and Underground Space Technology, 24(6), 2009, pp. 634-646.

4. Arjnoi, P., Jeong, J. H., Kim, C. Y., and Park, K. H., "Effect of drainage conditions on porewater pressure distributions and lining stresses in drained tunnels", Tunnelling and Underground Space Technology, 24(4), 2009, pp. 376-389.

5. Fernandez, G., and Moon, J., "Excavation-induced hydraulic conductivity reduction around a tunnel-Part 1: Guideline for estimate of ground water inflow rate", Tunnelling and Underground Space Technology, 25(5), 2010, pp. 560-566.

6. Yoo, C., Lee, Y. J., Kim, S. H., and Kim, H. T., "Tunnellinginduced ground settlements in a groundwater drawdown environment-A case history", Tunnelling and Underground Space Technology, 29, 2012, pp. 69-77.

7. Zhu, W. C., and Bruhns, O. T., "Simulating excavation damaged zone around a circular opening under hydromechanical conditions", International Journal of Rock Mechanics and Mining Sciences, 45(5), 2008, pp. 815-830.

8. Yang, T. H., Jia, P., Shi, W. H., Wang, P. T., and Yu, Q. L., "Seepage-stress coupled analysis on anisotropic characteristics of the fractured rock mass around roadway", Tunnelling and Underground Space Technology, 43, 2014, pp. 11-19.

\section{References}

9. Li, T. C., Li, S. C., Chen, W. Z., and Qiu, X. B., "Coupled fluidmechanical analysis of Xiamen subsea tunnel", Chinese Journal of Geotechnical Engineering, 26(3), 2004, pp. 397-401.

10. Ji, X. M., "Discussion on the Research of Coupled Solid and Fluid Flow in Tunnel Engineering", Chinese Journal of Underground Space and Engineering, 2(1), 2006, pp. 149-154.

11. Li, P. F., Zhang, D. L., Li, B., Fang, Q., and Sun, F., "Coupled Fluid-Solid Analysis of the Surrounding Rock Stability of the Subsea Tunnel during Construction Process", China Railway Science, 31(3), 2010, pp. 35-41.

12. Ji, Y. J., Liu, J. J., and Cheng, L. S., "Numerical simulation of tunnel excavation considering fluid solid coupling", Rock and Soil Mechanics, 32(4), 2011, pp. 1229-1233.

13. Zhang, Z. Q., He, B. G., Wang, Z. J., Li, H. Y., and Liu, Y. J., "Study of method and effect of high-position drainage of tunnel in water-rich fault", Rock and Soil Mechanics, 33(11), 2012, pp. 33593366.

14. Lai, J. X., Fan, H. B., and Shen, A. J., "Study on the drainage scheme of water-rich soft rock tunnel based on solid-fluid coupling", South-North Water Transfers and water Science \& Technology, 13(2), 2015, pp. 349-353.

15. Yang, J. H., Wang, S. R., Wang, Y. G., and Li, C. L., "Analysis of Arching Mechanism and Evolution Characteristics of tunnel pressure-arch", Jordan Journal of Civil Engineering, 9(1), 2015, pp. $125-132$. 